\title{
Bus accident severity and passenger injury: evidence from Denmark
}

\author{
Carlo Giacomo Prato • Sigal Kaplan
}

Received: 30 July 2012 / Accepted: 29 May 2013 / Published online: 14 June 2013

(C) The Author(s) 2013. This article is published with open access at SpringerLink.com

\begin{abstract}
Purpose Bus safety is a concern not only in developing countries, but also in the U.S. and Europe. In Denmark, disentangling risk factors that are positively or negatively related to bus accident severity and injury occurrence to bus passengers can contribute to promote safety as an essential principle of sustainable transit and advance the vision "every accident is one too many".

Methods Bus accident data were retrieved from the national accident database for the period 2002-2011. A generalized ordered logit model allows analyzing bus accident severity and a logistic regression enables examining occurrence of injury to bus passengers.

Results Bus accident severity is positively related to (i) the involvement of vulnerable road users, (ii) high speed limits, (iii) night hours, (iv) elderly drivers of the third party involved, and (v) bus drivers and other drivers crossing in yellow or red light. Occurrence of injury to bus passengers is positively related to (i) the involvement of heavy vehicles, (ii) crossing intersections in yellow or red light, (iii) open areas, (iv) high speed limits, and (v) slippery road surface.

Conclusions The findings of the current study provide a comprehensive picture of the bus safety situation in Denmark and suggest the necessity of further research into bus drivers' attitudes and perceptions of risks and road users' perceptions of bus operations. Moreover, these findings suggest the need for further training into bus drivers' hazard recognition skills and infrastructural solutions to forgive possible driving errors.
\end{abstract}

C. G. Prato $(\bowtie) \cdot$ S. Kaplan

Department of Transport, Technical University of Denmark,

Bygningstorvet 116B, 2800 Kgs. Lyngby, Denmark

e-mail: cgp@transport.dtu.dk

S. Kaplan

e-mail: siga@transport.dtu.dk
Keywords Bus safety $\cdot$ Bus passenger safety $\cdot$ Injury severity $\cdot$ Generalized ordered logit $\cdot$ Logistic regression

\section{Introduction}

Recent years have witnessed an increasing interest across world regions in enhancing bus safety as a result of the number of injuries and fatalities as well as high media exposure following mass casualty bus accidents (e.g., [8-10, 25]).

Bus safety is a major concern in developing countries where bus transport assumes a prominent role in assuring adequate and affordable accessibility to the vast majority of the population while promoting urban and rural development [25]. High accident rates for buses with respect to other vehicle types have been reported in India, Nepal, Tanzania, and Zimbabwe [25], Pakistan [22], Chile [13], Sri Lanka [17] and Bangladesh [8].

Bus safety is a concern also in the U.S. and Europe where, although bus transport is considered a safe mode, the number of injuries and fatalities is far from being negligible [8]. In the U.S., between 1999 and 2005 about 63,000 buses were involved in traffic accidents that resulted in 14,000 injuries and 325 fatalities every year [10]. In Europe, about 20,000 buses were implicated in traffic collisions that led to 30,000 injuries and 150 fatalities every year [14]. The interest in enhancing bus safety is reflected in the U.S. by the National Transportation Safety Board [24], with the insertion in the most wanted list of safety issues, and the House of Representative and the Senate, with the introduction of the new Motor-coach Enhanced Safety Act of 2011. The same interest is reflected in Europe by the European Commission, with the funding of projects such as European Coach and Bus Occupant Safety (ECBOS) and Road Safety in School Transport (RSST) to stimulate decision-makers on the issue.

Bus safety is a concern also in Denmark, where in 2000 the Danish Commission on Road Safety prepared a national 
plan for road safety covering the period between 2001 and 2012. The plan proposed the vision "every accident is one too many" as central strategic theme to be shared by all stakeholders and actors engaged in improving road safety. The vision set the path toward a future road system without road traffic accidents through mitigating and preventive measures. Although bus transport is considered a safe mode in Denmark, it is important to comprehend the risk factors behind the severity of accidents involving buses to design mitigating and preventive measures for the realization of the vision.

Interestingly, the increasing interest in bus safety is not reflected in the literature. Consequently, a number of basic questions remain largely overlooked [1, 12]. In particular, the question concerning the risk factors associated with bus accident severity and passenger injury severity remains overlooked [8].

In both Europe and other continents, the main research stream focused on risk factors related to bus accident rates and injury rates. A series of studies examined in Sweden the correlation between bus accident rates and acceleration behavior [2, 3, 5], economical driving [4], high temperatures [6], and drivers' absence behavior [7]. Another study examined in Finland the relationship between occupational injury rate and immigration status of bus drivers [30]. Bus accident rates were associated to drivers' working conditions, salary incentives and job satisfaction in Sri Lanka [17], and drivers' resting problems in Iran [28]. Bus accident frequency was related bus safety campaigns in Florida [29], traffic volumes and traffic control strategies in Canada [31], and demographic and behavioral characteristics of drivers in the U.S. [10].

Only a few studies concentrated on risk factors associated to accident severity. In Taiwan, accident rates were linked to bus operator characteristics independently for fatal, severe injury and minor injury accidents [11]. In Bangladesh, bus accident severity was modeled with an ordered probit with respect to risk factors such as weekday, time of day, traffic flow, traffic control, median availability, number of vehicles involved, and collision type [8]. In Florida, transit bus accident severity was modeled with a multinomial logit model with regard to traffic flow and road characteristics [12]. In Canada, injury in bus accidents was estimated with a series of binary logistic regressions in connection to traffic control and infrastructural factors [27]. In the U.S., bus accident severity was modeled with a generalized ordered logit in regard to risk factors such as drivers' demographics and behavior, collision partners' characteristics and behavior, infrastructural characteristics and environmental conditions [18]. In Greece, bus involvement was considered when comparing the severity of accidents inside and outside urban areas [32].

The current study provides insight into the risk factors related to the severity of accidents involving buses in Denmark, and hence proposes the first comprehensive analysis of bus accident severity in Europe. Moreover, the current study sheds light on the risk factors associated with the probability of injury occurrence to bus passengers, and hence introduces an additional perspective to the bus safety discussion. The examined risk factors consist of drivers' demographics and their behavior, third parties' characteristics, their drivers' demographics and behavior, infrastructure characteristics, environmental conditions, area- and timespecific control factors. Disentangling the factors that are positively or negatively related to bus accident severity as well as the factors that are positively or negatively associated with injury occurrence to bus passengers can contribute to raising the awareness of bus operators, drivers and road authorities to circumstances bearing risks to bus operations. This is an essential step toward promoting safety as an essential principle of sustainable transit, according to the widely accepted EU definition of sustainable transport [15], as well as advancing the "every accident is one too many" vision of the Danish Commission on Road Safety .

Bus accident data were retrieved from the national accident database for the period 2002-2011 of realization of the national safety plan. A generalized ordered logit model is used to analyze bus accident severity because of its ability in accommodating the ordered-response nature of severity while relaxing the proportional odds assumption and hence accommodating changes in variable effects across intermediate severity categories. A logistic regression is used to examine injury occurrence to bus passengers because of its ability in testing the association between the probability of occurrence and the related potential risk factors.

The remainder of the paper is organized as follows. Section 2 presents the bus accident data. Section 3 introduces the methodology applied for modeling accident severity and injury occurrence of bus passengers. Section 4 presents model estimation results. Section 5 discusses major findings and introduces conclusive remarks.

\section{Data}

Bus accident data were extracted from the national accident database maintained by the Danish Road Directorate. Danish police compiles reports of accidents occurred on Danish roads, and the road directorate records information about the accident, the persons and the vehicles involved. Information about the accidents includes type, weekday and time of day, severity level, collision manner, number of vehicles and road users involved, infrastructure characteristics, light and weather conditions, land use and area jurisdiction. Information about the persons involved comprises demographics, intoxication level, restraint use, license validity and injury severity. Information about the vehicles involved contains make and model, weight, registration date, maneuvers, and collision point.

Given the focus of the present study, accidents involving buses in the period between 2002 and 2011 are analyzed. The 
Table 1 Sample characteristics

\begin{tabular}{|c|c|c|c|c|}
\hline Variables & Categories & Percent & Categories & Percent \\
\hline \multirow[t]{2}{*}{ Accident severity $^{\mathrm{a}}$} & Damage only & $66.1 \%$ & Severe injury & $15.9 \%$ \\
\hline & Light injury & $14.4 \%$ & Fatal injury & $3.5 \%$ \\
\hline \multirow[t]{3}{*}{ Bus driver's age $^{\mathrm{a}}$} & 24 years old or less & $1.7 \%$ & $45-54$ years old & $31.4 \%$ \\
\hline & $25-34$ years old & $10.3 \%$ & 55-64 years old & $26.6 \%$ \\
\hline & $35-44$ years old & $26.3 \%$ & 65 years old or more & $3.8 \%$ \\
\hline Bus driver's gender ${ }^{\mathrm{a}}$ & Male & $86.7 \%$ & Female & $13.3 \%$ \\
\hline Bus driver's intoxication $^{\mathrm{a}}$ & No & $99.3 \%$ & Yes & $0.7 \%$ \\
\hline \multirow[t]{2}{*}{ Bus driver's maneuver $^{\mathrm{a}}$} & Straight & $67.0 \%$ & Left turn & $13.8 \%$ \\
\hline & Right turn & $8.5 \%$ & Standing & $10.7 \%$ \\
\hline \multirow[t]{3}{*}{ Bus driver's maneuver at intersection ${ }^{\mathrm{c}}$} & Red light crossing & $8.4 \%$ & & \\
\hline & Yellow light crossing & $2.3 \%$ & Stop or right of way & $24.4 \%$ \\
\hline & Green light crossing & $30.9 \%$ & No traffic control & $33.9 \%$ \\
\hline Bus type $^{a}$ & Regular & $70.2 \%$ & Other & $29.8 \%$ \\
\hline Accident type $^{\mathrm{a}}$ & Single-vehicle & $17.4 \%$ & Multi-vehicle & $82.6 \%$ \\
\hline \multirow[t]{4}{*}{ Other party involved $^{\mathrm{b}}$} & Pedestrian & $10.7 \%$ & Car & $51.6 \%$ \\
\hline & Cyclist & $11.6 \%$ & Van & $6.9 \%$ \\
\hline & Moped & $4.3 \%$ & Heavy vehicles & $4.8 \%$ \\
\hline & Motorcycle & $1.5 \%$ & Object & $8.7 \%$ \\
\hline \multirow[t]{3}{*}{ Other party's age (years) ${ }^{\mathrm{b}}$} & 24 or less & $23.6 \%$ & $45-54$ & $13.7 \%$ \\
\hline & $25-34$ & $20.2 \%$ & $55-64$ & $11.3 \%$ \\
\hline & $35-44$ & $20.4 \%$ & 65 or more & $10.8 \%$ \\
\hline Other party's gender ${ }^{\mathrm{b}}$ & Male & $64.4 \%$ & Female & $35.6 \%$ \\
\hline Other party's intoxication ${ }^{\mathrm{b}}$ & No & $93.7 \%$ & Yes & $6.3 \%$ \\
\hline Other party's seatbelt use ${ }^{\mathrm{b}}$ & No & $31.8 \%$ & Yes & $68.2 \%$ \\
\hline \multirow[t]{2}{*}{ Other driver's maneuver ${ }^{\mathrm{d}}$} & Straight & $70.5 \%$ & Left turn & $16.9 \%$ \\
\hline & Right turn & $7.5 \%$ & Standing & $5.1 \%$ \\
\hline \multirow[t]{3}{*}{ Other driver's maneuver at intersection ${ }^{c}$} & Red light crossing & $13.9 \%$ & & \\
\hline & Yellow light crossing & $2.3 \%$ & Stop or right of way & $24.4 \%$ \\
\hline & Green light crossing & $25.5 \%$ & No traffic control & $33.9 \%$ \\
\hline Accident location $^{\mathrm{a}}$ & Section & $49.6 \%$ & Intersection & $50.4 \%$ \\
\hline \multirow[t]{2}{*}{ Speed limit ${ }^{\mathrm{a}}$} & $50 \mathrm{~km} / \mathrm{h}$ or less & $64.2 \%$ & $70 \mathrm{~km} / \mathrm{h}$ & $5.9 \%$ \\
\hline & $60 \mathrm{~km} / \mathrm{h}$ & $10.0 \%$ & $80 \mathrm{~km} / \mathrm{h}$ or more & $19.9 \%$ \\
\hline \multirow[t]{2}{*}{ Number of lanes ${ }^{\mathrm{a}}$} & One & $8.3 \%$ & & \\
\hline & Two & $65.8 \%$ & Three or more & $25.8 \%$ \\
\hline \multirow[t]{2}{*}{ Light conditions $^{\mathrm{a}}$} & Daylight & $76.5 \%$ & & \\
\hline & Darkness & $17.6 \%$ & Artificial light & $5.9 \%$ \\
\hline Visibility $^{\mathrm{a}}$ & Yes & $95.1 \%$ & No & $4.9 \%$ \\
\hline Surface conditions ${ }^{\mathrm{a}}$ & Dry & $67.7 \%$ & Slippery & $32.3 \%$ \\
\hline Weather conditions ${ }^{\mathrm{a}}$ & Good & $82.2 \%$ & Adverse & $17.8 \%$ \\
\hline \multirow[t]{5}{*}{ Year $^{\mathrm{a}}$} & 2002 & $12.3 \%$ & 2007 & $11.3 \%$ \\
\hline & 2003 & $12.0 \%$ & 2008 & $8.8 \%$ \\
\hline & 2004 & $11.1 \%$ & 2009 & $8.2 \%$ \\
\hline & 2005 & $10.2 \%$ & 2010 & $9.1 \%$ \\
\hline & 2006 & $9.9 \%$ & 2011 & $7.1 \%$ \\
\hline \multirow[t]{2}{*}{ Season $^{a}$} & Spring & $23.9 \%$ & Autumn & $25.8 \%$ \\
\hline & Summer & $25.6 \%$ & Winter & $24.7 \%$ \\
\hline Day $^{\mathrm{a}}$ & Weekday & $83.2 \%$ & Weekend & $16.8 \%$ \\
\hline \multirow[t]{2}{*}{ Time of day ${ }^{\mathrm{a}}$} & 06:00-09:00 & $15.7 \%$ & & \\
\hline & 09:00-15:00 & $39.0 \%$ & $18: 00-21: 00$ & $10.2 \%$ \\
\hline
\end{tabular}


Table 1 (continued)

\begin{tabular}{llllr}
\hline Variables & Categories & Percent & Categories & Percent \\
\hline Land use $^{\mathrm{a}}$ & $15: 00-18: 00$ & $25.3 \%$ & $21: 00-06: 00$ & \\
& Residential (sparse) & $15.9 \%$ & & \\
& Residential (dense) & $27.5 \%$ & Industrial & $11.9 \%$ \\
Area $^{\mathrm{a}}$ & Commercial & $7.8 \%$ & Open areas & MidJutland \\
& Copenhagen & $40.7 \%$ & South Jutland & $8.6 \%$ \\
& Sealand & $17.6 \%$ & Fyn & $8.2 \%$ \\
\hline
\end{tabular}

\footnotetext{
${ }^{\mathrm{a}}$ Percent of accidents

${ }^{\mathrm{b}}$ Percent of collision partners

${ }^{\mathrm{c}}$ Percent of accidents at intersections

${ }^{\mathrm{d}}$ Percent of drivers among collision partners
}

10 years cover the same period for the implementation of the road safety plan of the Danish Commission on Road Safety and guarantee an adequately large sample size. Although the dataset extracted from the national accident database presents the limitation common to all datasets based on police reports, namely the risk of under-reporting, nonetheless it serves satisfactorily the scope of the current study. Firstly, it should be noted that police records are the main data source for injury severity analysis in the road safety literature because of their richness. The alternative data source, namely hospital records, often contains only partial information about the accident and suffers from recall and response bias among interviewed patients [19]. Secondly, it should be noted that accidents involving buses are likely not to go unobserved, and hence the risk of under-reporting is far less prominent.

The dataset for model estimation contains 3,434 cases. Danish police differentiates between (i) damage only accidents where property damage and bruises occur, (ii) light injury accidents where proper medical treatment is required, (iii) severe injury accidents where temporarily or permanently incapacitating injuries are sustained (e.g., lesions, fractures, head trauma), and (iv) fatal accidents where a person involved in the accident dies within 30 days from the its occurrence. The distribution of the maximum injury severity in the dataset counts $66.1 \%$ of damage only accidents, $15.9 \%$ of light injury accidents, $23.8 \%$ of serious injury accidents, and $3.5 \%$ of fatal accidents.

The sample characteristics are described in Table 1. Interestingly, the vast majority of the accidents were a collision between a bus and third parties $(82.6 \%)$. Most buses were in regular scheduled services $(70.2 \%)$, mainly in the off-peak period between morning and afternoon rush hours $(39.0 \%)$ and in the evening or night $(20.0 \%)$. The third parties were mainly vehicles $(63.2 \%)$, but counted also a significant percentage of vulnerable road users $(28.1 \%)$. Accidents took place in equal proportion between sections (49.6\%) and intersections (50.4\%), two out of every three happened on two-lane roads $(65.8 \%)$ and in areas with low speed limits $(64.2 \%)$, and almost one out of every three on slippery road surfaces $(32.3 \%)$. Most bus drivers were male $(86.7 \%)$ with a prevalence of 25 55 years old $(67.9 \%)$. From a driving behavior perspective, a staggering $10.7 \%$ of bus drivers crossed intersections in red or yellow light and an expectedly low $0.7 \%$ was intoxicated. Among third parties' drivers, an even more astounding $16.2 \%$ crossed intersections in red or yellow light, $6.3 \%$ was intoxicated and $31.8 \%$ did not wear seatbelts.

\section{Methodology}

The current study analyzes bus accident severity and injury occurrence to bus passengers by applying the prominent approach of econometric modeling.

\subsection{Model of bus accident severity}

Bus accident severity is defined in the current study as the highest degree of severity suffered by any road user in an accident where a bus was involved. Given that accident severity is coded by the Danish police according to a fourpoint scale from the lowest to the highest level $(0=$ property damage only, $1=$ light injury, $2=$ severe injury, 3 =fatal injury), an ordered-response model appears the most suitable approach.

As accident severity is an ordered-response discrete variable, an ordered logit model can be written in terms of probability of injury severity $j$ for a given accident $i$ as (see, e.g., [21]):

$P\left(y_{i}>j\right)=\frac{\exp \left(X_{i} \beta^{\prime}-\phi_{j}\right)}{1+\exp \left(X_{i} \beta^{\prime}-\phi_{j}\right)} \quad j=1,2, \ldots, \quad M-1$ 
where $X_{i}$ is a vector of explanatory variables of accident $i, \beta$ is a vector of parameters to be estimated, $\phi_{j}$ are cut-off points for the thresholds of the ordered model to be estimated, and $M$ is the number of categories of the ordered-response variable.

The ordered logit model assumes equal relationship between each pair of injury severity levels, but this proportional odds assumption may be violated by all or part of the explanatory variables and hence may be relaxed in order to avoid incorrect, incomplete or misleading results. The generalized ordered logit model expresses the probability of injury severity $j$ for a given accident $i$ as (see, e.g., [21]):

$$
\begin{gathered}
P\left(y_{i}>j\right)=\frac{\exp \left(X_{1 i} \beta_{1}^{\prime}+X_{2 i} \beta_{2 \mathrm{j}}^{\prime}-\phi_{j}\right)}{1+\exp \left(X_{1 i} \beta_{1}^{\prime}+X_{2 i} \beta_{2 \mathrm{j}}^{\prime}-\phi_{j}\right)} \\
j=1,2, \ldots, M-1
\end{gathered}
$$

where $\beta_{1}$ is a vector of parameters associated to a subset $X_{1 i}$ of explanatory variables that do not violate the proportional odds assumption, and $\beta_{2 j}$ is a vector of parameters associated to a subset $X_{2 i}$ of explanatory variables that vary according to the cut-off points of the ordered model.

The probability of injury severity has a closed-form expression and the parameters $\beta_{1}, \beta_{2 j}$ and $\phi_{j}$ are estimated through the maximization of the log-likelihood function $L L$ :

$L L=\sum_{n=1}^{N} \sum_{j=1}^{J} d_{n j} \ln P\left(y_{i}>j\right)$

where $N$ is the number of accidents, and $d_{n j}$ is equal to 1 if accident $\mathrm{n}$ results in severity category $j$ and 0 otherwise. A Brant test prior to model estimation verifies the null hypothesis that the estimated coefficients in an ordered logit model satisfy the parallel odds assumption on the basis of their respective values and variances $[21,35]$. The ordered logit model is sufficient in the case that the proportional odds assumption is met, but the generalized ordered logit model is preferable in the case that the assumption is violated [21, 35]. The generalized ordered logit model has been recently implemented in the road safety context for analyzing injury severity in left-turn crashes [33], investigating traffic congestion effects on the severity of road crashes [26], and examining bus accident severity in the U.S. [18].

In the current study, the generalized ordered logit model is fitted by a user-written program in Stata [35]. As injury severity is defined according to four categories, the model is identified by estimating parameters for the three thresholds between the four categories (i.e., for each threshold, the reference category is the lowest one). As the interpretation of the coefficients of intermediate injury severity levels requires caution, since the sign of the estimate does not always determine the direction of the effect of the intermediate outcomes $[34,36]$, elasticities are calculated for the four injury severity categories. As the explanatory variables are generally indicator variables (i.e., $0 / 1$ variables) and the probabilities are not differentiable with respect to indicator variables, direct pseudo-elasticities are calculated as the percentage change in probability when an indicator variable is switched (i.e., from 0 to 1 or from 1 to 0 ) [34]:

$E_{x_{j n k}}^{P\left(y_{j}>j\right)}=\frac{P\left(y_{i}>j\right)\left[\text { given } x_{j n k}=1\right]-P\left(y_{i}>j\right)\left[\text { given } x_{j n k}=0\right]}{P\left(y_{i}>j\right)\left[\text { given } x_{j n k}=0\right]}$

where $x_{j n k}$ is the k-th independent variable associated with injury severity $j$ for accident $n$. The average direct pseudoelasticity for each injury severity $j$ is computed as the average over the entire sample of accidents, since the direct pseudoelasticity is calculated for each injury severity $j$ and each accident $n$ [20].

\subsection{Model of injury occurrence to bus passengers}

The injury occurrence to bus passengers is coded in the current study as a binary variable equal to 1 when bus passengers are severely or fatally injured, and 0 otherwise. Out of 3,434 accidents in the ten-year period examined, 289 accidents resulted in at least one severe injury to bus passengers.

Given the premise, a logistic regression is the most suitable model to test the association between the probability of injury occurrence and the related potential risk factors (see [21, 36]):

$\pi\left(X_{i}\right)=\frac{\exp \left[g\left(X_{i}\right)\right]}{\exp \left[g\left(X_{i}\right)\right]+1}$

where $\pi$ is the probability of injury occurrence to bus passengers, and $g$ is the logit transformation of the $X_{i}$ explanatory variables associated to accident $i$. The logit transformation is expressed as a linear in parameters function (see $[21,36]$ ):

$$
\begin{aligned}
g\left(X_{i}\right)=\ln \left[\frac{\pi\left(X_{i}\right)}{1-\pi\left(X_{i}\right)}\right]= & \beta_{o}+\beta_{1} X_{1 i}+\beta_{2} X_{2 i}+\ldots \\
& +\beta_{q} X_{q i}+\ldots+\beta_{Q} X_{Q i}
\end{aligned}
$$

where $X_{q i}$ is the q-th explanatory variable associated to accident $i$, with $q$ varying from 1 to $Q$.

As the interpretation of the coefficients is easier in terms of probability change, the odds of injury occurrence to bus passengers are calculated as the probability of the injury occurring divided by the probability of the injury not occurring. The odds ratio is defined as $O R=\exp \left(\beta_{q}\right)$ and expresses the relative amount by which the odds of injury occurrence increase (when the $O R$ is greater than 1.0) or decrease (when the $O R$ is lower than 1.0) at the switch of the indicator variable from 0 to 1 (see $[21,36])$. The logistic regression was fitted in Stata, and the selection of the variable to enter the model followed a procedure consisting in verifying through a 
likelihood ratio test that the added variable was significant at the 0.10 level.

\section{Results}

The generalized ordered logit model and the logistic regression were estimated with several combinations of the explanatory variables described in the data section, and hypothesis testing was performed for variable significance and category aggregation. In addition, year-specific dummy variables were estimated to control for unobserved factors varying over the ten-year period such as time-trends in injury severity, and region-specific dummy variables were estimated to control for unobserved factors varying across regions in Denmark.

\subsection{Generalized ordered logit model results}

In the current study, a Brant test was performed prior to model estimation in order to check the need for the generalized ordered logit model instead of the ordered logit model. The test results revealed that the null hypothesis of equal coefficients across thresholds could not be rejected for some of the explanatory variables (e.g., bus drivers' maneuvers, slippery surface), but could be rejected for others (e.g., pedestrian and cyclist involvement, speed limits). Accordingly, the generalized ordered logit model was preferred not to introduce bias by incorrectly assuming that all the variables met the proportional odds assumption.

Table 2 reports the estimation results and Table 3 the average direct pseudo-elasticities of the generalized ordered logit model. Variables were retained if they were significant at least at the 0.10 level when meeting the proportional odds assumption and at the 0.05 level for at least one of the thresholds when varying across them. Year-specific and area-specific effects were retained because informative about the presence or absence of these effects. The Hosmer and Lemeshow [16]was used to test the goodness-of-fit of the model, and a chi-square statistic of 9.99 for $8^{\circ}$ of freedom (i.e., 10 quantiles were used for grouping the data) produced a p-value equal to 0.2658 , which is nonsignificant and hence indicates that the data fit the model well.

\subsubsection{Bus driver ś demographics and behavior}

Results show that bus accident severity is related only partially to the demographics and more substantially to the behavior of the bus driver. The very limited cases of bus driver intoxication are not significantly associated with variations in the probability of injuries and fatalities.

The bus driver's gender is not significantly related to bus accident severity, while the age is positively associated with an increase in the probability of higher severity only for bus drivers 24 years old or younger. The remaining age groups do not exhibit significant differences in the probability of injuries or fatalities in accidents involving buses. Notably, the share of bus drivers 24 years old or younger involved in bus accidents is only $1.8 \%$.

Bus accident severity is associated with the maneuvers performed by the bus drivers. With respect to the bus going straight, any turning maneuver and any standing position is associated with lower probability of higher accident severity. Turning left is related to a decrease in the probability of severe injuries by $15.8 \%$ and fatalities by $18.3 \%$. These reductions reach respectively $39.4 \%$ and $44.2 \%$ for buses turning right and respectively $43.9 \%$ and $49.1 \%$ for buses standing. Notably, two out of every three buses experience accidents while going straight, and hence the most severe consequences happen for the most frequent occurrence.

When considering the approach to intersections, bus accident severity increases when bus drivers exhibit illegal behavior. With respect to entering an intersection without traffic control, having the bus driver crossing with red or yellow light increases the probability of light injury by $10.2 \%$, severe injury by $16.0 \%$, and death by $19.2 \%$. Notably, crossing with red or yellow light produced significantly comparable estimates and were combined. Interestingly, greater likelihood of higher accident severity is observed when bus drivers approach an intersection with a stop or a right of way sign. With respect to approaching an intersection without traffic control, these situations rise the probability of light, severe and fatal injury by $16.8 \%, 28.5 \%$ and $35.4 \%$, respectively.

\subsubsection{Third partyś characteristics and behavior}

Expectedly, the type of third party is correlated to bus accident severity. In particular, with respect to collisions between buses and cars, the harshest consequences occur when vulnerable road users are involved.

The involvement of pedestrians, cyclists, moped riders and motorcyclists greatly increases the probability of higher severity. The likelihood of light injury grows from $43.9 \%$ for motorcyclists to $86.1 \%$ for pedestrians, the likelihood of severe injury rises from $150.8 \%$ for motorcyclists to $247 \%$ for pedestrians, and the likelihood of death increases from $230.0 \%$ for cyclists to $375.2 \%$ for pedestrians. With respect to collisions with cars, the probabilities augment also for accidents involving vans and heavy vehicles at the rate of 7.3-23.4 \% for light injuries, $11.7-43.2 \%$ for severe injuries, and $14.2-55.7 \%$ for fatal injuries.

As for bus drivers, the gender of the third parties involved in the accident is not correlated to the severity outcome of the accident. Unlike for bus drivers, the age of the third parties involved is related to higher levels of accident severity. The direst consequences are for collision partners over 45 years old, with a sharp increase of $43.0 \%$ and $121.5 \%$ in the probability of severe injuries and deaths for elderly over 
Table 2 Model estimation results

\begin{tabular}{|c|c|c|c|c|}
\hline \multirow[t]{2}{*}{ Variables } & \multirow[t]{2}{*}{ Characteristics } & \multicolumn{3}{|c|}{ Threshold between: } \\
\hline & & 0 and 1 & 1 and 2 & 2 and 3 \\
\hline \multirow[t]{2}{*}{ Bus driver's age } & 24 years old or less & $0.318^{* *}$ & $0.393^{* *}$ & $1.066^{* *}$ \\
\hline & 25 years old or more ${ }^{a}$ & - & - & - \\
\hline \multirow[t]{4}{*}{ Bus driver's maneuver } & Going straight $^{\mathrm{a}}$ & - & - & - \\
\hline & Turning right ${ }^{\mathrm{b}}$ & $-0.557^{* * *}$ & $-0.557^{* * *}$ & $-0.557^{* * *}$ \\
\hline & Turning left ${ }^{\mathrm{b}}$ & $-0.200^{*}$ & $-0.200^{*}$ & $-0.200^{*}$ \\
\hline & Standing $^{\mathrm{b}}$ & $-0.625^{* * *}$ & $-0.625^{* * *}$ & -0.625 \\
\hline \multirow[t]{3}{*}{ Bus driver's maneuver at intersections } & Red or yellow light crossed ${ }^{b}$ & $0.190^{* *}$ & $0.190^{* *}$ & $0.190^{* *}$ \\
\hline & Right of way ${ }^{\mathrm{b}}$ & $0.320^{* *}$ & $0.320^{* *}$ & $0.320^{* *}$ \\
\hline & No traffic control ${ }^{\mathrm{a}}$ & - & - & - \\
\hline \multirow[t]{8}{*}{ Third party involved } & Pedestrian & $2.410^{* * *}$ & $2.066^{* * *}$ & $1.793^{* * *}$ \\
\hline & Cyclist & $1.583^{* * *}$ & $1.590^{* * *}$ & $1.355^{* * *}$ \\
\hline & Moped $^{\text {b }}$ & $1.600^{* * *}$ & $1.600^{* * *}$ & $1.600^{* * *}$ \\
\hline & Motorcycle $^{\mathrm{b}}$ & $1.337^{* * *}$ & $1.337^{* * *}$ & $1.337^{* * *}$ \\
\hline & $\mathrm{Car}^{\mathrm{a}}$ & - & - & - \\
\hline & $\operatorname{Van}^{\mathrm{b}}$ & $0.137^{*}$ & $0.137^{*}$ & $0.137^{*}$ \\
\hline & Heavy vehicles ${ }^{\mathrm{b}}$ & $0.460^{* *}$ & $0.460^{* *}$ & $0.460^{* *}$ \\
\hline & Object $^{\mathrm{b}}$ & $0.422^{* * *}$ & $0.422^{* * *}$ & $0.422^{* * *}$ \\
\hline \multirow[t]{4}{*}{ Third party's age } & Less than 45 years old ${ }^{\mathrm{a}}$ & - & - & - \\
\hline & $45-54$ years old $^{\mathrm{b}}$ & $0.393^{* * *}$ & $0.393^{* * *}$ & $0.393^{* * *}$ \\
\hline & $55-64$ years old $^{\mathrm{b}}$ & $0.331^{* * *}$ & $0.331^{* * *}$ & $0.331^{* * *}$ \\
\hline & 65 years old or more & $0.393^{* * *}$ & $0.623^{* * *}$ & $1.239^{* * *}$ \\
\hline \multirow[t]{2}{*}{ Third party's behavior } & Alcohol consumption & $0.727^{* * *}$ & $0.515^{* * *}$ & 0.203 \\
\hline & No restraint use & $0.286^{* * *}$ & $0.324^{* * *}$ & $0.372^{*}$ \\
\hline \multirow[t]{4}{*}{ Third party's maneuver } & Going straight $\mathrm{t}^{\mathrm{a}}$ & - & - & - \\
\hline & Turning right ${ }^{\mathrm{b}}$ & $-0.637^{* * *}$ & $-0.637^{* * *}$ & $-0.637^{* * *}$ \\
\hline & Turning left ${ }^{\mathrm{b}}$ & $-0.216^{*}$ & $-0.216^{*}$ & $-0.216^{*}$ \\
\hline & Standing and parking ${ }^{\mathrm{b}}$ & $-0.442^{*}$ & $-0.442^{*}$ & $-0.442^{*}$ \\
\hline \multirow[t]{2}{*}{ Third party's maneuver at intersection } & Red or yellow light crossed ${ }^{\mathrm{b}}$ & $0.441^{* * *}$ & $0.441^{* * *}$ & $0.441^{* * *}$ \\
\hline & Right of way ${ }^{b}$ & $0.249^{*}$ & $0.249^{*}$ & $0.249^{*}$ \\
\hline \multirow[t]{3}{*}{ Speed limit } & $50 \mathrm{~km} / \mathrm{h}$ or $\operatorname{less}^{\mathrm{a}}$ & - & - & - \\
\hline & $60-70 \mathrm{~km} / \mathrm{h}$ & $0.317^{* *}$ & 0.169 & $0.659^{* *}$ \\
\hline & $80 \mathrm{~km} / \mathrm{h}$ or more & $0.834^{* * *}$ & $0.705^{* * *}$ & $1.626^{* * *}$ \\
\hline \multirow[t]{2}{*}{ Surface conditions } & Dry $^{\mathrm{a}}$ & - & - & - \\
\hline & Slippery (wet, snow, ice) ${ }^{\mathrm{b}}$ & $0.162^{*}$ & $0.162^{*}$ & $0.162^{*}$ \\
\hline \multirow[t]{4}{*}{ Land use } & Residential $^{\mathrm{b}}$ & $-0.173^{*}$ & $-0.173^{*}$ & $-0.173^{*}$ \\
\hline & Commercial $^{\mathrm{b}}$ & $-0.244^{*}$ & $-0.244^{*}$ & $-0.244^{*}$ \\
\hline & Industrial $^{\mathrm{b}}$ & $-0.452^{* * *}$ & $-0.452^{* * *}$ & $-0.452^{* * *}$ \\
\hline & Open areas ${ }^{\mathrm{a}}$ & - & - & - \\
\hline \multirow[t]{4}{*}{ Time of day } & $06-09^{\mathrm{a}}$ & - & - & - \\
\hline & $09-15^{\mathrm{b}}$ & $0.249^{* * *}$ & $0.249^{* *}$ & $0.249^{* *}$ \\
\hline & $15-18^{\mathrm{b}}$ & $-0.134^{*}$ & $-0.134^{*}$ & $-0.134^{*}$ \\
\hline & $18-06$ & $0.168^{*}$ & $0.496^{* *}$ & $0.649^{* *}$ \\
\hline \multirow[t]{5}{*}{ Year-specific effects } & $2002^{\mathrm{a}}$ & - & - & - \\
\hline & $2003^{b}$ & -0.239 & -0.239 & -0.239 \\
\hline & $2004^{\mathrm{b}}$ & 0.080 & 0.080 & 0.080 \\
\hline & $2005^{\mathrm{b}}$ & $-0.473^{* * *}$ & $-0.473^{* * *}$ & $-0.473^{* * *}$ \\
\hline & $2006^{\mathrm{b}}$ & -0.140 & -0.140 & -0.140 \\
\hline
\end{tabular}


Table 2 (continued)

\begin{tabular}{|c|c|c|c|c|}
\hline \multirow[t]{2}{*}{ Variables } & \multirow[t]{2}{*}{ Characteristics } & \multicolumn{3}{|c|}{ Threshold between: } \\
\hline & & 0 and 1 & 1 and 2 & 2 and 3 \\
\hline \multirow{11}{*}{ Area-specific effects } & $2007^{\mathrm{b}}$ & -0.148 & -0.148 & -0.148 \\
\hline & $2008^{\mathrm{b}}$ & $-0.372^{* *}$ & $-0.372^{* *}$ & $-0.372^{* *}$ \\
\hline & $2009^{b}$ & $-0.412^{* *}$ & $-0.412^{* *}$ & $-0.412^{* *}$ \\
\hline & 2010 & $-0.712^{* * *}$ & -0.192 & -0.091 \\
\hline & 2011 & $-0.925^{* * *}$ & $-0.491^{* *}$ & $-1.356^{* *}$ \\
\hline & Copenhagen $^{\mathrm{a}}$ & - & - & - \\
\hline & Sealand ${ }^{\mathrm{b}}$ & 0.079 & 0.079 & 0.079 \\
\hline & North Jutland ${ }^{\mathrm{b}}$ & $0.537^{* * *}$ & $0.537^{* * *}$ & $0.537^{* * *}$ \\
\hline & MidJutland ${ }^{\mathrm{b}}$ & $0.546^{* * *}$ & $0.546^{* * *}$ & $0.546^{* * *}$ \\
\hline & South Jutland ${ }^{\mathrm{b}}$ & -0.004 & -0.004 & -0.004 \\
\hline & Fyn $^{\mathrm{b}}$ & 0.191 & 0.191 & 0.191 \\
\hline Constant & & $-1.716^{* * *}$ & $-2.701^{* * *}$ & $-5.169^{* * *}$ \\
\hline Number of observations & & & & 3434 \\
\hline Log-likelihood at estimates & & & & -2891.62 \\
\hline McFadden rho-square & & & & 0.1262 \\
\hline
\end{tabular}

\footnotetext{
${ }^{a}$ Base category

${ }^{\mathrm{b}}$ Tested constraint for parallel lines

* Significant at the 0.10 level

${ }^{* * *}$ Significant at the 0.05 level

${ }^{* * * *}$ Significant at the 0.01 level
}

65 years old. Moreover, the consumption of alcohol and the failure to wear seatbelts by drivers of the third parties are also associated with an increase in accident severity. Interestingly, these two negligent behaviors exhibit different trends, as alcohol intoxication relates to an increase in the likelihood of light $(60.3 \%)$ rather than severe $(54.5 \%)$ or fatal $(21.7 \%)$ injuries, while non-use of seatbelts relates to a rise in the probability of fatal $(37.8 \%)$ rather than severe $(26.6 \%)$ or light (11.9\%) injuries.

Similarly to bus drivers, maneuvers of the third parties' drivers are correlated to accident severity. As for bus drivers, it is observed a decrease in the probability of injuries and fatalities occurring when turning or standing with respect to going straight. Unlike for bus drivers, the increase of the likelihood of light, severe and fatal injuries is more pronounced when the third parties' drivers cross with red or yellow light $(22.6 \%, 40.8 \%, 52.0 \%$, respectively) than when they approach a stop or right of way sign (13.2\%, $21.8 \%, 26.8 \%$, respectively).

\subsubsection{Infrastructure and environmental characteristics}

Only the speed limit is significantly correlated to bus accident severity among infrastructural characteristics, as the equal repartition between section and intersection located accidents and the number of lanes resulted into non-significant differences in the probability of injuries and fatalities. Relatively to speed limits equal to or lower than $50 \mathrm{~km} / \mathrm{h}$, speed limits of 60 $70 \mathrm{~km} / \mathrm{h}$ are associated with an increase of $31.1 \%$ in light injuries, $5.5 \%$ in severe injuries and $81.4 \%$ in fatal injuries. Speed limits of $80 \mathrm{~km} / \mathrm{h}$ or more observe more pronounced effects, with respectively $55.7 \%, 39.5 \%$ and $277.2 \%$ raises for light, severe and fatal injuries.

Only surface conditions and time of day are significantly correlated to bus accident severity. Weather conditions are expectedly correlated with surface conditions, while visibility and light conditions are partially correlated with time of day, and hence they are not in the model specification to avoid multi-collinearity problems. With respect to dry surfaces, slippery conditions increase the probability of light injuries by $8.7 \%$, severe injuries by $13.4 \%$, and deaths by $16.0 \%$. With respect to morning hours, daily off-peak hours are positively related to higher likelihood of severe and fatal injuries by $20.9-25.1 \%$, while nightly off-peak hours are associated with an even higher probability of severe and fatal injuries by $42.9-82.7 \%$.

\subsubsection{Land-use, area-specific effects and time-specific effects}

Accidents that occur in open areas are associated with a moderately greater probability of lower bus accident severity with respect to areas with residential, commercial or industrial 
Table 3 Average pseudo elasticities

\begin{tabular}{|c|c|c|c|c|c|}
\hline Variable & Categories & Damage only & Light injury & Severe injury & Fatal injury \\
\hline \multirow[t]{2}{*}{ Bus driver's age } & 24 years old or less & $-10.3 \%$ & $8.5 \%$ & $52.2 \%$ & $66.3 \%$ \\
\hline & 25 years old or more ${ }^{a}$ & - & - & - & - \\
\hline \multirow[t]{4}{*}{ Bus driver's maneuver } & Going straight ${ }^{\mathrm{a}}$ & - & - & - & - \\
\hline & Turning right & $15.4 \%$ & $-29.6 \%$ & $-39.4 \%$ & $-44.2 \%$ \\
\hline & Turning left & $5.9 \%$ & $-10.8 \%$ & $-15.8 \%$ & $-18.3 \%$ \\
\hline & Standing & $17.1 \%$ & $-33.1 \%$ & $-43.9 \%$ & $-49.1 \%$ \\
\hline \multirow[t]{3}{*}{ Bus driver's maneuver at intersection } & Red or yellow light crossed & $-5.9 \%$ & $10.2 \%$ & $16.0 \%$ & $19.2 \%$ \\
\hline & Right of way & $-10.2 \%$ & $16.8 \%$ & $28.5 \%$ & $35.4 \%$ \\
\hline & No traffic control ${ }^{\mathrm{a}}$ & - & - & - & - \\
\hline \multirow[t]{8}{*}{ Third party involved } & Pedestrian & $-77.4 \%$ & $86.1 \%$ & $247.0 \%$ & $375.2 \%$ \\
\hline & Cyclist & $-53.7 \%$ & $51.6 \%$ & $184.2 \%$ & $230.0 \%$ \\
\hline & Moped & $-54.6 \%$ & $44.3 \%$ & $182.2 \%$ & $338.0 \%$ \\
\hline & Motorcycle & $-46.1 \%$ & $43.9 \%$ & $150.7 \%$ & $256.3 \%$ \\
\hline & $\mathrm{Car}^{\mathrm{a}}$ & - & - & - & - \\
\hline & Van & $-4.3 \%$ & $7.3 \%$ & $11.7 \%$ & $14.2 \%$ \\
\hline & Heavy vehicles & $-15.1 \%$ & $23.4 \%$ & $43.2 \%$ & $55.7 \%$ \\
\hline & Object & $-13.7 \%$ & $21.8 \%$ & $38.7 \%$ & $49.1 \%$ \\
\hline \multirow[t]{4}{*}{ Third party's age } & Less than 45 years old ${ }^{\mathrm{a}}$ & - & - & - & - \\
\hline & $45-54$ years old & $-12.0 \%$ & $21.2 \%$ & $32.4 \%$ & $38.5 \%$ \\
\hline & 55-64 years old & $-10.1 \%$ & $17.8 \%$ & $27.4 \%$ & $32.5 \%$ \\
\hline & 65 years old or more & $-12.0 \%$ & $1.2 \%$ & $43.0 \%$ & $121.5 \%$ \\
\hline \multirow[t]{2}{*}{ Third party's behavior } & Alcohol consumption & $-24.4 \%$ & $60.3 \%$ & $54.5 \%$ & $21.7 \%$ \\
\hline & No restraint use & $-8.8 \%$ & $11.9 \%$ & $26.6 \%$ & $37.8 \%$ \\
\hline \multirow[t]{4}{*}{ Third party's maneuver } & Going straight ${ }^{\mathrm{a}}$ & - & - & - & - \\
\hline & Turning right & $17.1 \%$ & $-33.5 \%$ & $-43.5 \%$ & $-48.3 \%$ \\
\hline & Turning left & $6.6 \%$ & $-11.7 \%$ & $-17.7 \%$ & $-21.0 \%$ \\
\hline & Standing and parking & $12.4 \%$ & $-23.6 \%$ & $-31.8 \%$ & $-35.8 \%$ \\
\hline \multirow[t]{3}{*}{ Other party's maneuver at intersection } & Red or yellow light crossed & $-14.3 \%$ & $22.6 \%$ & $40.8 \%$ & $52.0 \%$ \\
\hline & Right of way & $-7.9 \%$ & $13.2 \%$ & $21.8 \%$ & $26.8 \%$ \\
\hline & No traffic control ${ }^{\mathrm{a}}$ & - & - & - & - \\
\hline \multirow[t]{3}{*}{ Speed limit } & $50 \mathrm{~km} / \mathrm{h}$ or less ${ }^{\mathrm{a}}$ & - & - & - & - \\
\hline & $60-70 \mathrm{~km} / \mathrm{h}$ & $-10.1 \%$ & $31.1 \%$ & $5.5 \%$ & $81.4 \%$ \\
\hline & $80 \mathrm{~km} / \mathrm{h}$ or more & $-27.4 \%$ & $55.7 \%$ & $39.5 \%$ & $277.2 \%$ \\
\hline \multirow[t]{2}{*}{ Surface conditions } & Dry $^{\mathrm{a}}$ & - & - & - & - \\
\hline & Slippery (wet, snow, ice) & $-5.0 \%$ & $8.7 \%$ & $13.4 \%$ & $16.0 \%$ \\
\hline \multirow[t]{4}{*}{ Land use } & Residential & $5.3 \%$ & $-9.3 \%$ & $-14.2 \%$ & $-16.8 \%$ \\
\hline & Commercial & $7.2 \%$ & $-13.2 \%$ & $-19.0 \%$ & $-21.9 \%$ \\
\hline & Industrial & $12.7 \%$ & $-24.2 \%$ & $-32.9 \%$ & $-37.2 \%$ \\
\hline & Open areas ${ }^{\mathrm{a}}$ & - & - & - & - \\
\hline \multirow[t]{4}{*}{ Time of day } & $06-09^{\mathrm{a}}$ & - & - & - & - \\
\hline & $09-15$ & $-7.7 \%$ & $13.3 \%$ & $20.9 \%$ & $25.1 \%$ \\
\hline & $15-18$ & $4.0 \%$ & $-7.2 \%$ & $-10.8 \%$ & $-12.7 \%$ \\
\hline & $18-06$ & $-5.3 \%$ & $-25.1 \%$ & $42.9 \%$ & $82.7 \%$ \\
\hline \multirow[t]{6}{*}{ Year-specific effects } & $2002^{\mathrm{a}}$ & - & - & - & - \\
\hline & 2003 & $7.0 \%$ & $-12.9 \%$ & $-18.6 \%$ & $-21.5 \%$ \\
\hline & 2004 & $-2.5 \%$ & $4.3 \%$ & $6.7 \%$ & $8.1 \%$ \\
\hline & 2005 & $13.3 \%$ & $-25.3 \%$ & $-34.5 \%$ & $-39.0 \%$ \\
\hline & 2006 & $4.2 \%$ & $-7.6 \%$ & $-11.2 \%$ & $-13.1 \%$ \\
\hline & 2007 & $4.4 \%$ & $-8.0 \%$ & $-11.8 \%$ & $-13.7 \%$ \\
\hline
\end{tabular}


Table 3 (continued)

\begin{tabular}{|c|c|c|c|c|c|}
\hline Variable & Categories & Damage only & Light injury & Severe injury & Fatal injury \\
\hline \multirow{10}{*}{ Area-specific effects } & 2008 & $10.7 \%$ & $-20.0 \%$ & $-27.7 \%$ & $-31.6 \%$ \\
\hline & 2009 & $11.7 \%$ & $-22.1 \%$ & $-30.4 \%$ & $-34.5 \%$ \\
\hline & 2010 & $19.1 \%$ & $-72.1 \%$ & $-16.3 \%$ & $-8.6 \%$ \\
\hline & 2011 & $23.5 \%$ & $-71.2 \%$ & $-29.5 \%$ & $-81.2 \%$ \\
\hline & Copenhagen $^{\mathrm{a}}$ & - & - & - & - \\
\hline & Sealand & $-2.4 \%$ & $4.2 \%$ & $6.6 \%$ & $7.9 \%$ \\
\hline & North Jutland & $-17.7 \%$ & $27.0 \%$ & $51.0 \%$ & $66.4 \%$ \\
\hline & MidJutland & $-17.7 \%$ & $28.0 \%$ & $50.2 \%$ & $64.0 \%$ \\
\hline & South Jutland & $0.1 \%$ & $-0.2 \%$ & $-0.4 \%$ & $-0.4 \%$ \\
\hline & Fyn & $-6.0 \%$ & $10.2 \%$ & $16.6 \%$ & $20.2 \%$ \\
\hline
\end{tabular}

areas. The reduction in the likelihood of severe and fatal injuries is $14.2-16.8 \%$ for residential areas, $19.0-21.9 \%$ for commercial areas, and 32.9-37.2\% for industrial areas.

Area-specific effects show that, with respect to the reference area of Greater Copenhagen, only Mid and North Jutland witness an increase of about $50 \%$ of the probability of having severe bus accidents and about $65 \%$ of the likelihood of having fatal bus accidents. The remaining areas, namely the rest of Sealand, the island of Fyn, and South Jutland, do not exhibit significant differences in the probability of severity outcomes.

Year-specific effects control for unobserved factors such as time-trends or traffic variation across the years, and hence absorb possible confounding effects from the explanatory variables. With respect to accidents occurring in 2002, decreases in the likelihood of injuries and fatalities are observed throughout the years, to reflect a general improvement of the road safety situation as aspired by the Danish Commission on Road Safety. However, variations are neither always significant nor clearly trending down. Decreases are more pronounced for 2005, but non-significant for 2003 and 2004, as well as for 2008, but non-significant for 2006 and 2007. Only for 2011 decreases in the probabilities of injuries and fatalities are over $50 \%$, but the non-significant variations in 2010 suggests the proof of existence of clear timetrends being inconclusive.

\subsection{Logistic regression results}

Table 4 presents the estimation results of the logistic regression model in terms of odds ratio of injury occurrence to bus passengers. Following likelihood ratio tests, variables were retained if they were significant at least at the 0.10 level, while year-specific effects were retained because informative about possible unobserved time-trends. It should be noted that bus driver's intoxication does not enter the model specification not because non-significant, but because perfectly correlated with the outcome being at least one severely injured bus passenger.

Bus driver's gender and age are not significantly related to injury occurrence to bus passengers, but performed maneuvers are. Going straight implies having injuries to bus passengers about twice as likely with respect to the bus standing, turning left or turning right. With respect to crossing an intersection without traffic control, no significant difference on the probability of bus passenger injury is observed for bus drivers approaching stop or right of ways signs. However, significant increases are shown for bus drivers crossing in red light $(50.2 \%)$ or yellow light $(60.5 \%)$.

The involvement of a third party is highly related to injury occurrence to bus passengers. While considering colliding with a car as the reference case, accidents with vulnerable road users (i.e., pedestrians, cyclists, moped riders, motorcyclists) have less severe consequences with the probability of on-board injury occurrence reducing by a factor between 2 and 3. The likelihood of injury occurrence to bus passengers slightly increases by $20.9 \%$ when a bus collides with a van and substantially rises by $316.1 \%$ when a bus collides with a heavy vehicle. Interestingly, the likelihood of on-board injury occurrence largely grows $(186.3 \%)$ when a bus crashes into an object (e.g., tree, pole, wall).

As for bus drivers, third parties' gender and age are not significantly associated with on-board injury occurrence, but performed maneuvers are. Standing and turning maneuvers show the previously observed tendency of reducing the probability of injury occurrence to bus passengers with respect to going straight. When approaching intersections, illegal behavior such as crossing in red and yellow light greatly increases (60.8\% and $100.1 \%$, respectively) the likelihood of bus passenger injury. Interestingly, no significant correlation has been uncovered between alcohol intoxication of third parties' drivers and on-board injury occurrence.

Similarly to the bus accident severity model, the regression shows significant estimates for the odds ratio of speed 
Table 4 Logistic regression of injury occurrence to bus passengers
Significance with respect to odds ratio equal to 1.0

* Significant at the 0.10 level

** Significant at the 0.05 level

${ }^{* * *}$ Significant at the 0.01 level

Variable
Bus driver's maneuver
Bus driver's maneuver at intersection

Third party involved

Third party's maneuver

Third party's maneuver at intersection

Speed limit

Surface conditions

Land use

Time of day

Year-specific effects

Log-likelihood at estimates

McFadden rho-square
Categories

Odds ratio

Going straight ${ }^{\mathrm{a}}$

Turning right

Turning left

Standing

Red light crossed

Yellow light crossed

No traffic control ${ }^{\mathrm{a}}$

Pedestrian

Cyclist

Moped

Motorcycle

$\mathrm{Car}^{\mathrm{a}}$

Van

Heavy vehicles

Object

Going straight ${ }^{\mathrm{a}}$

Turning right

Turning left

Standing and parking

Red light crossed

Yellow light crossed

No traffic control ${ }^{\mathrm{a}}$

$70 \mathrm{~km} / \mathrm{h}$ or less ${ }^{\mathrm{a}}$

$80 \mathrm{~km} / \mathrm{h}$ or more

Dry $^{\text {a }}$

Slippery (wet, snow, ice)

Residential

Commercial or Industrial $^{\mathrm{a}}$

Open areas

$0.464^{* * *}$

$0.498^{* * *}$

$0.446^{* * *}$

$1.502^{*}$

$1.605^{*}$

$0.545^{* *}$

$0.451^{* * *}$

$0.481^{* *}$

$0.336^{*}$

$-$

$1.209^{*}$

$4.161^{* * *}$

$2.863^{* * *}$

$0.413^{* * *}$

$0.590^{* * *}$

$0.724^{*}$

$1.608^{* *}$

$2.001^{*}$

$1.426^{*}$

$1.163^{*}$

$1.146^{*}$

$1.379^{*}$

06-09

$09-15$

$1.101^{*}$

$0.662^{* *}$

$0.729^{*}$

$0.738^{*}$

21-06

$2002^{\mathrm{a}}$

2003

2004

2005

2006

2007

2008

0.893

$0.611^{* *}$

0.706

$0.435^{* * *}$

$0.609^{* *}$

$0.587^{* *}$

0.817

$0.517^{* * *}$

2010

0.748

3434

$-719.19$

0.1096 
limits, surface conditions and time of day. An increase in the probability of on-board injury occurrence is related to speed limits over $80 \mathrm{~km} / \mathrm{h}(42.6 \%)$, slippery surface conditions $(16.3 \%)$ and daily off-peak hours (10.1\%). With respect to morning peak hours, a decrease by factors between one-third and half in the likelihood of injury occurrence to bus passengers is associated with afternoon peak and nightly off-peak hours.

Land use variables suggest that injuries occur to bus passengers more likely in open areas (37.9\%) and residential areas $(14.6 \%)$ than in commercial and industrial areas. Yearspecific effects control for unobserved factors such as timetrends and suggest that, with respect to 2002, there is a general decrease in the probability of injury occurrence to bus passengers. However, not always variations are significant and no clear time-trend emerges.

\section{Discussion and conclusions}

The current study provides insight into risk factors that are positively or negatively related to the variation of the probability of bus accident severity and injury occurrence to bus passengers, and hence stimulates thoughts concerning the necessity to raise the awareness of bus operators, drivers and road authorities about circumstances that bear risk in bus operations.

Gender and age of bus drivers are not correlated with either injury severity or on-board injury occurrence, with the exception of young drivers under 24 years old increasing the probability of severe injuries by $52.2 \%$ and fatal injuries by $66.3 \%$. Notably, the percentage of young drivers involved in bus accidents is extremely low (1.8\%) and most bus drivers $(67.9 \%)$ are between 25 and 55 years old. This finding is in opposition with results for the U.S. where young and elderly drivers were related to increased bus accident severity [18]. It should be noted that bus operators in Denmark are extremely active in promoting pleasant and safe environment to passengers with the campaign "Chauffører med karakter" that leads to the election of the best bus driver of the year [23]. Possibly, bus operators could further enhance the smooth entrance in the rotation of young drivers by possibly extending the current first few weeks of supervision by more experienced drivers.

From the driving behavior perspective, the current study highlights the necessity of training bus drivers to avoid illegal behavior, recognize hazards and manage critical situations. Bus accidents in intersections counted $10.7 \%$ cases of bus drivers and $16.2 \%$ cases of third parties' drivers crossing in red or yellow light. This illegal behavior translates in higher probability of having harsher consequences for every party involved in general, and for the bus passengers in particular. As previous studies highlight the existence of correlation between bus accident rates and acceleration behavior $[2,3,5]$, research is necessary in the tendency of bus drivers to cross in yellow or red light, with one reason possibly being late and attempting to avoid further delays by stopping at the red light. Moreover, research is necessary in the ability for bus drivers to recognize the hazard of other drivers crossing in red light and in the possibility for traffic engineers to design traffic control solutions forgiving driving errors.

The current study suggests that hazard recognition training could be beneficial to the mitigation of some risk factors. A first example is that bus accident severity reaches higher levels and injury occurrence on-board becomes more likely when both the buses and the third parties proceed straight with respect to when they either stand or turn. Possibly, drivers are more attentive to the context while performing maneuvers requiring particular attention (e.g., turning right while avoiding pedestrians and cyclists, turning left while avoiding approaching vehicles) rather than simply driving straight. A second example concerns the involvement of vulnerable road users that greatly increases the probability of higher bus accident severity. Possibly, on the one hand bus drivers should be more vigilant when approaching areas with large numbers of vulnerable road users (e.g., the city of Copenhagen with large shares of cyclists), and on the other hand the vulnerable road users should be more wary of the dangers when maneuvering around buses. Concurrently, research could explore the perception of bus operation by road users, in particular vulnerable ones and heavy vehicle drivers. A third example regards the involvement of heavy vehicles that largely rises the likelihood of bus passenger injury. Possibly, bus drivers should be more cautious when driving in the proximity of heavy vehicles because of the involved large masses and the potential severe outcomes.

From the infrastructure perspective, the current study did not find significant differences neither for bus accident location in sections or intersections, nor for number of lanes. Similarly to bus accidents in the U.S. [18], speed limits are positively correlated to higher likelihood of injuries and fatalities. In particular, fatalities are associated with speed limits of $80 \mathrm{~km} / \mathrm{h}$ or more with an increase in their likelihood of $277.2 \%$, and bus passenger injuries are related to the same limits with a rise in their probability of $42.6 \%$. As speed limits in Denmark may be considered proxies for the location of the accident inside or outside urban areas, it should be noted that the current results are different from recent findings of negative correlation between accident severity and bus involvement in both urban and rural roads in Greece [32]. Although most bus accidents occur in sections with speed limits of $50 \mathrm{~km} / \mathrm{h}$ or less, it appears necessary to investigate further the modality of collisions on rural roads with high speed limits.

Surface conditions are correlated to bus accident severity and bus passenger injury probability. However, the measured effects in terms of increase in the probability of higher 
severity and injury occurrence are relatively mild and suggest that the road maintenance plan administered by the Danish road directorate likely mitigates the consequences of bus accidents. Notably, bus accidents are almost equally distributed across seasons, across weekdays and across time of day. Only time of day is related to accident severity with off-peak hours during both day and night increasing the probability of direr consequences for all persons involved in general and bus passengers in particular. Possibly, the organization of the shifts and the driving times could account for the need of the drivers to adapt to different traffic conditions within the same shift, as well as to different climate conditions in light of findings relating bus accident rates to high temperatures in Sweden [6].

Summarizing, the findings of the current study provide a comprehensive picture of the bus safety situation in Denmark and suggest the necessity of further research into bus drivers' attitudes and perceptions of risks and road users' perceptions of bus operations. Moreover, these findings suggest the need for further training into bus drivers' hazard recognition skills and infrastructural solutions to forgive possible driving errors, as well for maintenance of road surfaces and management of traffic and shifts across the day. Generally, this comprehensive picture is a very important step towards developing measures able to mitigate bus accident severity and promote bus passenger safety in order to realize the "every accident is one too many" vision of the Danish Commission on Road Safety.

Open Access This article is distributed under the terms of the Creative Commons Attribution License which permits any use, distribution, and reproduction in any medium, provided the original author(s) and the source are credited.

\section{References}

1. af Wåhlberg AE (2004) Characteristics of low speed accidents with buses in public transport: part II. Accident Anal Prev 36:63-71

2. af Wåhlberg AE (2004) The stability of driver acceleration behavior, and a replication of its relation to bus accidents. Accident Anal Prev 36:83-92

3. af Wåhlberg AE (2007) Aggregation of driver celeration behavior data: effects on stability and accident prediction. Safety Sci 45:487500

4. af Wåhlberg AE (2007) Long-term effects of training in economical driving: fuel consumption, accidents, driver acceleration behavior and technical feedback. Int J Ind Ergonom 37:333-343

5. af Wåhlberg AE (2008) The relation of non-culpable traffic incidents to bus drivers' celeration behavior. J Safety Res $39: 41-46$

6. af Wåhlberg AE (2008) If you can’t take the heat: influences of temperature on bus accident rates. Safety Sci 46:66-71
7. af Wåhlberg AE, Dorn L (2009) Absence behavior as traffic crash predictor in bus drivers. J Safety Res 40:197-201

8. Barua U, Tay R (2010) Severity of urban transit bus crashes in Bangladesh. J Adv Transport 44:34-41

9. Björnstig U, Albertsson P, Björnstig J, Bylund P-O, Falkmer T, Petzäll J (2005) Injury events among bus and coach occupants: non-crash injuries as important as crash injuries. IATSS Res 29:79-87

10. Blower D, Green PE (2010) Type of motor carrier and driver history in fatal bus crashes. Transport Res Rec 2194:37-43

11. Chang HL, Yeh CC (2005) Factors affecting the safety performance of bus companies-The experience of Taiwan bus deregulation. Safety Sci 43:323-344

12. Chimba D, Sando T, Kwigizile V (2010) Effect of bus size and operation to crash occurrences. Accident Anal Prev 42:20632067

13. Estache A, Gómez-Lobo A (2005) Limits to competition in urban bus services in developing countries. Transport Rev 25:139-158

14. ECBOS (2004) Final publishable report - enhanced coach and bus occupant safety. http://www.unece.org/fileadmin/DAM/trans/doc/ 2004/wp29grsg/TRANS-WP29-GRSG-86-inf04e.pdf

15. EU Council of Ministers (2001) Strategy for integrating environment and sustainable development into the transport policy. http:// corporate.skynet.be/sustainablefreight/trans-counci-conclusion-05-0401.htm

16. Hosmer DW, Lemeshow S (1989) Applied logistic regression. Wiley, New York

17. Jayatilleke AU, Nakahara S, Dharmaratne SD, Jayatilleke AC, Poudel KC, Jimba M (2009) Working conditions of bus drivers in the private sector and bus crashes in Kandy district, Sri Lanka: a case-control study. Injury Prev 15:80-86

18. Kaplan S, Prato CG (2012) Risk factors associated with bus accident severity in the United States: a generalized ordered logit model. J Safety Res 43:171-180

19. Kim JK, Kim S, Ulfarsson GF, Porrello LA (2007) Bicyclist injury severities in bicycle-motor vehicle accidents. Accident Anal Prev $39: 238-251$

20. Kim JK, Ulfarsson GF, Shankar VN, Mannering FL (2010) A note on modeling pedestrian-injury severity in motorvehicle crashes with the mixed logit model. Accident Anal Prev 42:1751-1758

21. Long JS (1997) Regression models for categorical and limited dependent variables. Sage Publications, Thousand Oaks

22. Mirza S, Mirza M, Chotani H, Luby S (1999) Risky behavior of bus commuters and bus drivers in Karachi, Pakistan. Accident Anal Prev 31:329-333

23. Movia Customer Center (2012) Bus driver with character (in Danish). http://www.buschauffor.dk/forside/

24. National Transportation Safety Board (2011) Most wanted list Bus occupant safety. http://www.ntsb.gov/safety/mwl.html

25. Pearce T, Maunder DAC, Mbara TC, Babu DM, Rwebangira T (2000) Bus accidents in India, Nepal, Tanzania, and Zimbabwe. Transport Res Rec 1726:16-23

26. Quddus MA, Wang C, Ison SG (2010) Road traffic congestion and crash severity: econometric analysis using ordered response models. J Transp Eng 136:424-435

27. Rahman M, Kattan L, Tay R (2011) Injury risks in collisions involving buses in Alberta. Proceedings of the 90th Annual Meeting of the Transportation Research Board, Washington, D.C.

28. Razmpa E, Niat KS, Saedi B (2011) Urban bus drivers' sleep problems and crash accidents. Indian J Otolaryngol 63:269-273

29. Rey JR, Hinebaugh D, Fernandez J (2002) Analysis of Florida transit bus crashes. Transport Res Rec 1791:26-34

30. Salminen S, Vartia M, Giorgiani T (2009) Occupational injuries of immigrant and Finnish bus drivers. J Safety Res 40:203-205 
31. Shahla F, Shalaby AS, Persaud BN, Hadayeghi A (2009) Analysis of transit safety at signalized intersections. Transport Res Rec 2102:108-114

32. Theofilatos A, Graham DJ, Yannis G (2012) Factors affecting accident severity inside and outside urban areas in Greece. Traffic Injury Prev 13:458-467

33. Wang X, Abdel-Aty M (2008) Analysis of left-turn crash injury severity by conflicting pattern using partial proportional odds models. Accident Anal Prev 40:1674-1682
34. Washington S, Karlaftis M, Mannering F (2003) Statistical and econometric methods for transportation data analysis. Chapman and Hall/CRC, Boca Raton

35. Williams R (2006) Generalized ordered logit/partial proportional odds models for ordinal dependent variables. Stata J $6: 58-82$

36. Wooldridge JM (2002) Econometric analysis of cross section and panel data. MIT Press, Cambridge 